\title{
A novel percutaneous strategy to chronic total occlusion of the native right coronary artery and associated vein graft aneurysm and giant pseudoaneurysm
}

Thet Hnin ${ }^{1}$, Amit Mandal ${ }^{1}$, Elliot Smith $^{2}$, Srikanth Iyengar ${ }^{1}$, Constantinos Missouris ${ }^{1}$, and Christopher Baker ${ }^{3}$

${ }^{1}$ Wexham Park Hospital

${ }^{2}$ Barts Health NHS Trust

${ }^{3}$ Hammersmith Hospital

August 11, 2020

\section{Hosted file}

Manuscript_JOCS.doc available at https://authorea.com/users/350085/articles/475027-a-novelpercutaneous-strategy-to-chronic-total-occlusion-of-the-native-right-coronary-arteryand-associated-vein-graft-aneurysm-and-giant-pseudoaneurysm

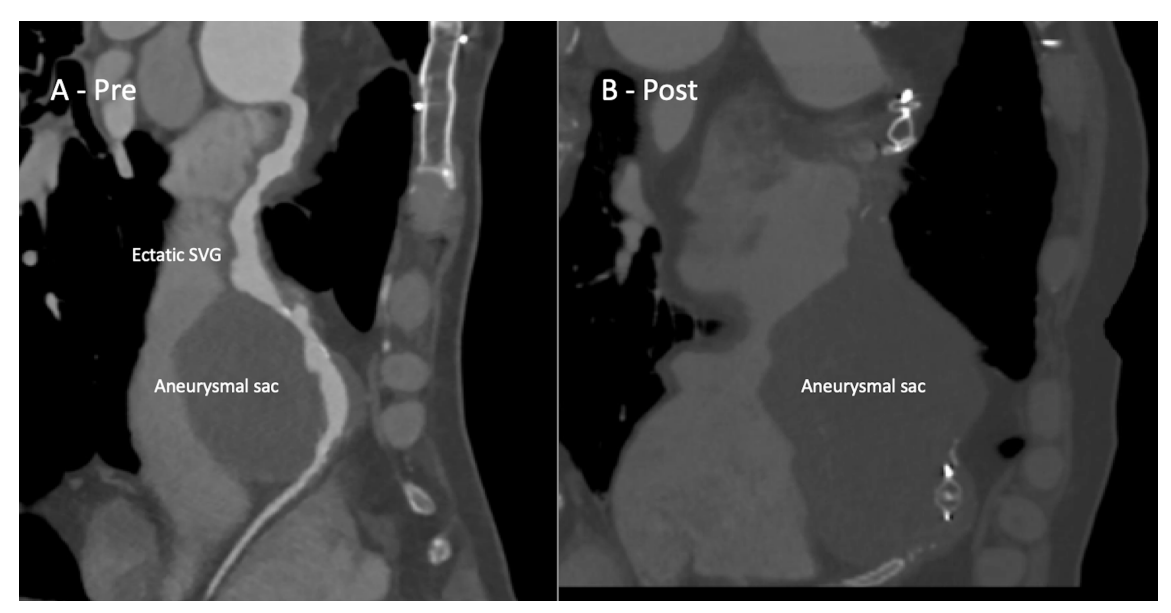




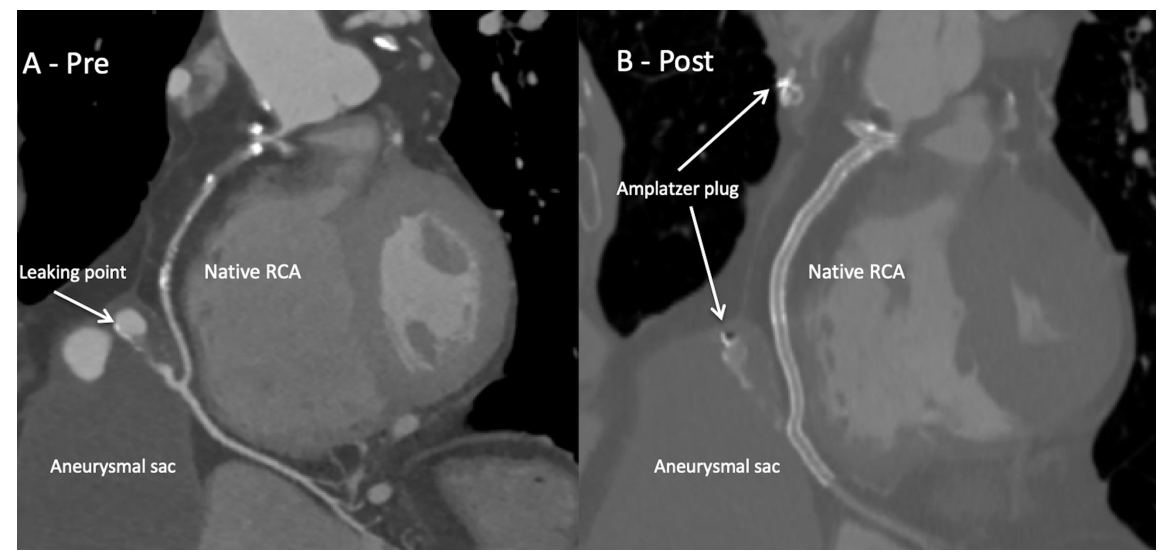

\section{Hosted file}

Video 1.mp4 available at https://authorea.com/users/350085/articles/475027-a-novelpercutaneous-strategy-to-chronic-total-occlusion-of-the-native-right-coronary-arteryand-associated-vein-graft-aneurysm-and-giant-pseudoaneurysm

\section{Hosted file}

Video 2.mp4 available at https://authorea.com/users/350085/articles/475027-a-novelpercutaneous-strategy-to-chronic-total-occlusion-of-the-native-right-coronary-arteryand-associated-vein-graft-aneurysm-and-giant-pseudoaneurysm

\section{Hosted file}

Video 3.mp4 available at https://authorea.com/users/350085/articles/475027-a-novelpercutaneous-strategy-to-chronic-total-occlusion-of-the-native-right-coronary-arteryand-associated-vein-graft-aneurysm-and-giant-pseudoaneurysm 